\title{
ENTRE BALÕES CHEIOS E VAZIOS: PROCESSOS DE SUBJETIVAÇÃO TECIDOS PELAS RELAÇÕES DE PODER-SABER NO CONTEXTO UNIVERSITÁRIO
}

\author{
Edileuza Santos do Nascimento Cruz \\ Marcelo de Almeida Ferreri ${ }^{\text {ii }}$
}

\begin{abstract}
RESUMO: O objetivo deste artigo é abordar processos de subjetivação tecidos pelas relações de podersaber no contexto universitário, no recorte da assistência estudantil, seguindo as pistas da experiência de si. Para tal, compartilhamos uma situação de vivência universitária, Entre balões cheios e vazios, narrativa tecida na rede de relações institucionais, e historiada com recursos da linguagem literária. A partir dela, acionamos a discussão de produção de subjetividade com as ideias de Michel Foucault sobre poder, tomado em sua positividade. A narrativa expõe modos de ser que se produzem marcados por entendimentos individualizantes, num processo de assujeitamento, pelas relações de poder-saber, as quais se situam numa dimensão que é coletiva, social e institucional.
\end{abstract}

Palavras-chave: Processos de subjetivação; Relações de poder-saber; Universidade; Assistência. Estudantil.

\section{BETWEEN FULL AND EMPTY BALLOONS: PROCESSES OF SUBJECTIVATION WOVEN BY POWER-KNOWLEDGE RELATIONSHIPS IN THE UNIVERSITY CONTEXT}

\begin{abstract}
The objective of this article is to approach subjectification processes woven by the relations of power-knowledge in the university context, in the context of student assistance, following the clues of the experience of self. To this end, we share a situation of university experience, Between full and empty balloons, a narrative woven into the network of institutional relations and historized with literary language resources. From it, we trigger the discussion of subjectivity production, with Michel Foucault's ideas about power, taken in its positivity. The narrative exposes ways of being that are produced marked by individualizing understandings, in a process of subjection, by the relations of power-knowledge, which are situated in a dimension that is collective, social and institutional.
\end{abstract}

Keywords: Subjectivation processes; Power-to-know relationships; University; Student Assistance.

Este $\operatorname{artigo~}^{\mathrm{iii}}$ trata de processos de subjetivação tecidos no contexto universitário, no recorte da assistência estudantil. A assistência estudantil é a área da universidade responsável pela execução da política de assistência estudantil, a qual tem como objetivo a ampliação das condições de permanência dos estudantes na educação pública superior, de acordo com o Decreto no 7.234 (BRASIL, 2010), que dispõe sobre o Programa Nacional de Assistência Estudantil (PNAES), e de acordo com a Resolução $n^{\circ}$ 08/2016/CONSU (UFS, 2016), que define as ações da assistência estudantil da Universidade Federal de Sergipe (UFS). Essa política busca oferecer ao estudante condições acesso, permanência e conclusão do curso superior, através de ações de moradia, alimentação e transporte, voltadas, prioritariamente, para o 
atendimento do que são entendidas como necessidades básicas dos alunos que se encontram em situação de vulnerabilidade socioeconômica.

Além disso, na assistência estudantil, há ações de caráter mais amplo, independentemente da situação socioeconômica do aluno, como projetos de atenção à saúde física e psicológica, projetos culturais e de esporte, lazer, cidadania, idiomas, inclusão digital e apoio pedagógico. A pretensão dessa política é que tais ações estejam articuladas ao ensino, à pesquisa e à extensão, com a finalidade de melhoria do desempenho educacional e da qualidade de vida do estudante na educação superior, no que diz respeito aos alunos de graduação presencial (FONAPRACE, 2012).

Foi, principalmente, pela atuação da Psicologia na Secretaria de Assistência Estudantil da UFS (SAES), que fomos suspeitando que as demandas de trabalho, referentes ao atendimento psicológico do aluno universitário, parecem se produzir pela teia de relações de poder-saber que nela se fazem presentes. Conforme entendimentos foucaultianos (FOUCAULT, 1993, 1995, 2006), essas relações remetem a uma dimensão que é coletiva e institucional, e não a questões focalizadas em determinados aspectos de caráter individual, como, muitas vezes, tendem a ser apresentadas. Assim, o objetivo deste artigo é abordar processos de subjetivação tecidos pelas relações que são travadas na universidade, pensando modos pelos quais essas relações vão nos produzindo e oferecendo certos tipos de relação conosco, com o outro, com o mundo e com o que fazemos.

A tentativa de estudar esse campo não diz respeito a uma intenção messiânica ou salvacionista; trata da necessidade de pensar a tessitura e as formas de estar nesses lugares institucionais, tomando a experiência de si como mote. Esta se constitui na articulação de práticas reguladoras, discursos de verdade e formas de subjetividade, as quais se situam numa dimensão mais ampla da experiência, que vai além do indivíduo, mas que, ao mesmo tempo, mostra-se no sujeito que se produz pelo modo como ele se relaciona consigo e com os outros, conforme nos diz Larrosa (2011). A experiência de si diz respeito à relação que o sujeito constitui consigo, através da qual vai estabelecendo, regulando e modificando o entendimento que tem em relação a si e ao outro. Ela é historicamente fabricada a partir complexos processos, nos quais se entrecruzam os discursos de campos de saber que definem a verdade do sujeito, os tipos de normatividade que dispõem práticas reguladoras do seu comportamento, e as formas de subjetividade, nas quais sua própria interioridade vai se constituindo (LARROSA, 2011).

A experiência de si se mostra como pista para o entendimento das formas pelas quais nos tornamos sujeitos em cada momento histórico, com seus processos de subjetivação. Processos de subjetivação se referem a um modo, que é intensivo e contingencial, pelo qual nos tornamos sujeitos; não é um estado ou estágio demarcado, nem se reduz à produção de características no sujeito. É o próprio movimento de produção do sujeito com um modo de funcionamento, de pensamento e de ação, que é coextensivo às forças que atravessam cada formação social (SILVA, R. 2005). 
Para Foucault (1995), o entendimento das formas pelas quais nos tornamos sujeitos deve tomar como ponto de partida o que ele denomina de racionalidades específicas, numa "nova economia das relações de poder" (p.233), ao invés de analisar uma racionalidade geral de uma cultura ou sociedade. Por racionalidades específicas, ele entende experiências concretas que se fazem pelas relações de poder e pelas estratégias de resistência diante da ação desse poder.

Isso fundamenta a ideia de estudar relações de poder e formas pelas quais nos tornamos sujeitos no contexto universitário de graduação, no recorte da assistência estudantil, ainda que Foucault (1995) nos alerte dos perigos em se estudar o poder nas instituições fechadas. Há o risco de se tomar as relações de poder, na instituição, na sua função essencialmente reprodutora, como se não houvesse nada além de modulações da lei e da coerção, para a conservação do seu aparelho e regras. O autor alerta que o poder não deve ser tomado como uma coisa ou substância secundária ao funcionamento da instituição, pois está em todo tecido social e não se explica por ele mesmo. Com isso, há o risco de cristalização da noção de poder, que, de acordo com a perspectiva analítica de Foucault (1995), só se dá em ato, em relação.

De acordo com Haskins (2015), a universidade é forjada pelas relações que estabelece com seu tempo, de acordo com as características do momento histórico. Há relações da universidade com a sociedade, da universidade com o conhecimento; e, de forma não dissociada dessas relações, há as que se dão entre os habitantes da universidade, aqueles que estão na função mais próxima de produzir e disseminar esse conhecimento, ou na função de prestar suporte para os processos de ensino-aprendizagem, esfera na qual se insere a assistência estudantil. Há alunos, há professores, há servidores técnicos, há servidores terceirizados e há, sobretudo, relações que subjetivam essas pessoas.

Enquanto produções históricas, os processos e relações que acontecem na universidade tendem a estar vinculados a certos valores, concepções e interesses do que seja o conhecimento, de como se deve produzir esse conhecimento e que sujeitos e verdades devem ser produzidos nesse contexto. Isso sinaliza que, além da clara função de produção de saber, a instituição universitária é, simultaneamente, local de circulação de poder, porque tende a sinalizar determinados rumos que as coisas, pessoas e relações devem tomar a partir dos saberes circulantes e estabelecidos.

$\mathrm{Na}$ universidade, esses processos parecem encontrar lugar privilegiado, na medida em que é instituição de formação educacional e que tem no saber seu objeto de excelência, saber esse que mantém relação indissociável com o poder, com as circunstâncias históricas, políticas e culturais, que atuam na produção daquilo que somos. Assim, problematizar a UFS, nos seus processos de subjetivação, pelo recorte da assistência estudantil, através de histórias que nela se produzem, é parte de uma andança que tenta perscrutar aquilo que somos, aquilo que temos nos tornado nesses terrenos, pois:

[...]os indivíduos e as instituições são produtos históricos envolvidos no processo de construção de outros produtos históricos. Se essa transitoriedade histórica nos 
constitui e constitui tudo que fazemos, a precaução elementar, tantas vezes repetida, é a de evitar a consideração do que somos e do que fazemos, de nossas ações e de seus resultados, como absoluto. Sendo a produção histórica de nós mesmos e de nossas instituições um processo, não cabe entendê-la como natural e inevitavelmente dada (SILVA, F. 2006, p. 192).

A partir dessas noções iniciais sobre experiência de si, processos de subjetivação e relações de poder-saber na universidade, compartilhamos a história "Entre balões cheios e vazios", que trata de modos de produção da vivência universitária na UFS. A história se construiu por um tom ensaístico, enquanto possibilidade de escrita que faz aproximação com os artifícios da linguagem literária (LARROSA, 2002, 2003; LEVY, 2003), numa tentativa de pensar a produção da realidade e daquilo que somos, para além do que estamos acostumados a depreender do uso corriqueiro da palavra.

Conforme apontamentos de Levy (2003), numa perspectiva blanchotiana, a linguagem literária abre a palavra para uma pluralidade de sentidos, desvinculando-a dos sentidos estabelecidos pelos poderes e saberes do nosso tempo, o que nos possibilita um olhar mais ampliado e desnaturalizador sobre a realidade em que vivemos. É pela irrealização ou negação do real que a literatura e a arte, de maneira geral, realizamse; nega-se o que se impõe como dado, e um outro mundo, outras possibilidades de vida brotam das palavras. O ficcionar cria outros mundos, diferentes do habitual, que se desprendem da ordem do reconhecimento, mas, ao mesmo tempo, não faz com que este mundo desapareça. Trata-se de desdobrar este mundo, as coisas, as palavras e os seres com outros signos, o que abre a possibilidade de se pensar outras formas de entendê-lo, de nele estar e de nele nos produzirmos (LEVY, 2003).

Nesse sentido, tomando como guia a experiência, enquanto aquilo que nos passa, nos toca e nos acontece (LARROSA, 2002, 2014), a vida cotidiana, na universidade, foi se fazendo narrativa, trazendo a possibilidade de acionar as ideias e ferramentas foucaultianas, para pensar essa realidade e os modos como temos nos produzido nela.

O “jogo" dos balões se teceu história pelas ressonâncias de situações relatadas por alunos, por conversas com outros profissionais da assistência estudantil e de outros setores do campus, bem como por situações e conversas informais, com as quais foi feito contato por acaso, em ocasiões à parte das rotinas de trabalho. Seus personagens não têm nomes específicos e suas falas ora se separam, ora se misturam, ressoando e se fazendo fala de muitos, pois o que interessou por em evidência não foram histórias ou "dramas individuais" necessariamente, mas aquilo que estas histórias e "dramas individuais" dizem sobre a instituição movida por relações de saber, que também são relações de poder, e como isso vai produzindo determinados modos de ser e de entender as coisas.

A história dos balões se fez escrita narrativa em abril de 2019, mas se refere a situações que ocorreram entre 2018 e 2019, principalmente, sem precisar tal cronologia com muita exatidão, pois esta 
história se encontra e se confunde com tantas outras histórias da assistência estudantil da UFS, o que faz diluir as fronteiras entre um acontecimento e outro, ainda que cada um assuma sua singularidade.

$* * * * * * * * * *$

\section{Entre balões cheios e vazios}

Certa feita, nos fins de uma conversa, perguntei para uma estudante: “o que acontece quando só usamos o nosso gás, quando ele somente sai e a gente não o repõe ou não consegue repor?”. Mesmo tendo feito a pergunta em tom metafórico e descontraído, a resposta não deixou de me surpreender, irrompendo além do que esperava, face às durezas que vinham sendo dispostas no assunto tratado: falávamos sobre o estar na universidade, de formas possíveis de viver neste terreno. Só que falávamos de formas em que nosso "gás" mais parece ser sugado do que abastecido; as vivências relatadas falavam desse esvaziamento. Sagaz e ludicamente, foi-me dito que, se o gás só sai, “o balão fica vazio, murcho”. Sem gás, o balão perde a forma e a leveza, não consegue flutuar ao ser impulsionado. Sem gás, o balão não flutua na universidade!

Nessa conversa de balóes cheios e vazios, era-me apresentado, por aluna com quem conversava, um cenário típico de "fracasso" educacional, que vinha se fazendo por reprovações sucessivas em determinadas disciplinas de um curso de Exatas, numa espécie de efeito dominó, no qual a perda de uma disciplina foi inviabilizando a possibilidade de matrícula em outras dos períodos subsequentes, para as quais a primeira era pré-requisito. Havia um "atraso" no curso, uma enorme insatisfação com ele, com a disciplina e, principalmente, consigo. Estava ali, bem à minha frente, um balão se esvaziando.

A queixa se apresentou sob o nome de ansiedade, com as feições de dificuldade de concentração, insônia e dificuldades de assimilar e resgatar informações. Alimentava-se de exigências de desempenho de excelência e de tentativas de controle do incontrolável, produzindo como resíduos pensamentos que se mostravam pesados demais para manter um balão flutuando. Tendia a localizar sobre si a "incapacidade" e a "incompetência" de obtenção de sucesso educacional. Havia muitas coisas pesando ali; coisas demais para que um "simples" balão tivesse importância suficiente para ser olhado. Ao mesmo tempo, ele pedia para ser olhado, porque estava mandando sinais de que estava murchando, tal como a febre nos dá o recado do nosso corpo, quando ele não vai bem.

O balão aqui em questão dizia fazer pesquisa, mas murchava ao perceber que fazer isso era só percorrer um trajeto já dado, conhecido e eleito como o melhor, indo por longos trechos emparedado, quase sempre segurado por um cordão, que deveria lhe prender a algo. Não visualizava espaço para apontar para onde gostaria de ir; se ousava tentar, era bruscamente puxado pelo cordão. Com isso, seu gás só diminuía. 
O "balão murcho" falava de uma dinâmica de curso em que a reprovação em massa em determinadas disciplinas é algo muito "natural”, até esperado por muita gente; apenas um número muito pequeno consegue passar pela "fina peneira”. Determinadas disciplinas desse curso, justamente algumas dessas de reprovação em massa, eram alvos do monopólio de um certo “condutor de balóes”, cuja metodologia de ensino ao "voo" fora apontada como muito incompativel pelo balão que estava a murchar. Essa não era uma "queixa" isolada, mas compartilhada por outros tantos balões, que vinham passando pela SAES. Havia uma clara insatisfação com o modo como as coisas ocorriam: os projetos das disciplinas, as formas e dinâmicas de avaliação, os quais eram exaltados pelo "mestre", que colocava tais formas de proceder no topo da excelência das universidades renomadas, precisamente, de uma nacionalmente conhecida, onde estivera fazendo seus estudos.

Então, nada mais “óbvio" que as turmas deveriam se adaptar àquilo, à tal metodologia, a melhor metodologia, a utilizada nas melhores universidades, que formam os melhores alunos. Tudo era "melhor", exceto a aprendizagem e desempenho dos alunos, que têm até duas disciplinas por semestre com o mesmo "condutor de balões"; que, no semestre seguinte, caso consigam avançar, terão mais disciplinas com o mesmo mestre, com a mesma metodologia. Isso chega a me lembrar de um certo slogan, importado da terra do Tio Sam, adaptado e utilizado no período ditatorial no Brasil, recentemente retomado, neste momento também de exceção: "Brasil, ame-o ou deixe-o”. E, depois de algumas tentativas, se o "amor" não acontece, muitos alunos deixam este território para cursar as mesmas disciplinas, com outros mestres e metodologias, em outros terrenos; partem na tentativa de fazer seus balões flutuarem noutros ares.

"Ele é até gente boa" e realmente acredita naquela metodologia; "o problema não é ele”; "não é nada pessoal"; "todo mundo sabe disso, mas ninguém fala”; "muita gente se incomoda, mas ninguém questiona”, seja pelo medo ou pelas "portas" que tal “condutor de balões” pode abrir; portas como um mestrado naquela renomada universidade, de onde ele alega ter trazido a dita metodologia. E isso não é blefe; uns dois alunos já foram parar lá, por tais portas; outros tantos alunos também querem passar por essa porta; é o caminho sinalizado para "inflar” balões. E isso chega a lembrar quase um ritual ascético, do "necessário" sofrimento, da submissão resignada a tal sofrimento, com vistas a uma superação indefinida de si e à obtenção da recompensa gloriosa prometida. Não é mera semelhança a lembrança da passagem dos eleitos pela "porta estreita".

Então, estudar, por essas vias, pode ser a “necessária” via crucis percorrida por cada sujeito individualmente, em busca de sua formação. E não é só de formação universitária e profissional de que os balões estão falando.

$* * * * * * * * * *$ 
A história traz situações relacionadas ao baixo desempenho educacional, reprovações e retenção num curso de Exatas, que aparecem associadas a determinados modos de funcionamento de algumas disciplinas monopolizadas por determinados professores, cujas metodologias de ensino, avaliação e cálculo das notas são tidas como desfavoráveis pelos alunos: por mais que tenham obtido êxito em quase todas as etapas que compõem a nota, basta apenas uma etapa abaixo do esperado, para que a nota total se torne desfavorável. De tão repetidas e naturalizadas, tais situações tendem a aparecer a partir dos desgastes e frustrações quanto ao desempenho educacional, transformando-se em sintoma, adoecimento, muitas vezes, entendidos, estritamente, no âmbito das "causas" individuais, aparentemente, à parte da dinâmica institucional de saber e poder, que produz as relações entre aqueles que operam as engrenagens universitárias.

A narrativa apresenta uma lógica individualizante que perpassa o entendimento dos "problemas", assim como das "soluções", produzidos nas relações na universidade, que não são só relações de ensinoaprendizagem, ainda que as coisas se deem, justifiquem-se e se encaminhem por meio delas. Na SAES, quem mais costuma procurar atendimento são os próprios estudantes em situação de insucesso educacional, que, por vezes, também se encontram em situação de sofrimento, como o balão que estava a murchar. $\mathrm{O}$ atendimento e orientação tendem a ser procurados para dar conta do "problema", "dificuldade", "falha" ou "sintoma", entendidos como causa do baixo desempenho. É a “ansiedade", o "nervosismo", que costumam ser colocados como produtores daquilo que atrapalha, como se a tal ansiedade ou nervosismo tivessem caído do nada e de paraquedas na vida de quem chega apresentando esse tipo de queixa.

No entanto, pelas ideias de Michel Foucault, entendemos que esse tipo de "queixa" e modos de estar na universidade, como exposto pelos balões, são produções de uma dinâmica que é coletiva, que percorre as engrenagens institucionais, tecendo-se pelas relações, que não são só de saber, mas também de poder. Ou seja, aquilo que tende a se apresentar no âmbito das questões individuais traz em si modos de ser, que são forjados a nível institucional e social.

A partir das ideias de Foucault (1999), no livro Vigiar e Punir, é possível identificar a universidade no rol das instituições por ele denominadas "disciplinares", ao lado de outras, como o hospital, o exército, a prisão, a indústria. Esses espaços, também chamados de instituições de sequestro, destacam-se, principalmente, por volta do século XVIII, pela utilização de uma forma de poder bastante peculiar, denominado poder disciplinar, que cumpria os objetivos de ordem, produtividade e produção de subjetividade nesses locais, a partir de uma lógica de dominação sutil, de forma que as pessoas a ela sujeitas tendiam a aceitá-la e naturalizá-la, incorporando-a numa relação de docilidade-utilidade. Essas instituições apresentam o uso maciço de poder, operacionalizado através dos métodos de controle minucioso do corpo e das suas forças, que constituem as disciplinas (FOUCAULT, 1999). 
Como destacam Ferreirinha e Raitz (2010), há toda uma tecnologia de organização do tempo e dos espaços, numa perspectiva hierárquica, que coloca essas instituições como prescritoras de comportamentos de forma homogeneizante. As disciplinas formam uma espécie de ligação entre as relações de poder, as relações de comunicação e as capacidades técnicas. Foucault (1995) nos diz que:

Não há, numa sociedade dada, um tipo geral de relações de equilíbrio entre as atividades finalizadas, os sistemas de comunicação e as relações de poder. Há, antes, diversas formas, diversos lugares, diversas circunstâncias em que estas interrelações se estabelecem sobre um modelo específico. Porém, há "blocos" nos quais o ajuste de capacidades, os feixes de comunicação e as relações de poder constituem sistemas regulados e concordes. [...] Estes blocos [...] constituem aquilo que podemos chamar, alargando um pouco o sentido da palavra, de "disciplinas" (FOUCAULT 1995, p. 241).

Nesse sentido, as disciplinas estariam presentes em ambientes, como uma instituição escolar, sob a forma de organização dos espaços, das atividades, das pessoas e da sua "vida interior", a partir dos lugares e funções assumidas nesse contexto. A história dos balões cheios e vazios traz aspectos disciplinares, que ainda se fazem presentes na instituição universitária, ainda que ela seja bem mais do que disciplina e venha se modulando na associação da disciplina com outras lógicas de controle mais sutis.

As situações trazidas na narrativa aparecem em torno da atividade do aprendizado, da aquisição de competências e de modos específicos de se fazer isso, a partir de determinadas atividades e modos de avaliação dessas atividades, o que também pressupõe um tipo de comportamento de concordância com a metodologia aplicada pelo professor. Há uma comunicação regulada para essa finalidade, que vai desde aquelas que giram em torno de um conteúdo específico, até a forma de comunicação estabelecida entre os estudantes e o professor, entre os estudantes, e entre estudantes e a assistência estudantil, que "permitem" ou não que certas coisas sejam ditas ou postas em questão, mesmo fora da sala de aula. Há procedimentos de poder e de controle, que não se dão só pela recompensa/punição em termos de notas; há metas a serem cumpridas; há uma decomposição da avaliação em várias partes para compor uma nota, através de uma fórmula específica; há posições demarcadas por uma hierarquia- professor e alunos, alunos bem-sucedidos e alunos malsucedidos etc. Há silenciamentos e, em torno disso, algumas camadas de naturalizações.

Veiga-Neto (2016) ressalta que as disciplinas funcionam em redes invisíveis, através de microscópicas divisões espaciais e temporais, que incidem sobre os corpos e os saberes, fazendo com que sejamos partes dessas redes, o que torna natural e aceitável a ação do poder disciplinar. Tal ordem de funcionamento não diz respeito, necessariamente, a uma manipulação irrestrita dos saberes ou dos sujeitos que os produzem. Aponta, sobretudo, para a complexidade de relações que se dão nesse tipo de instituição, e para os jogos de força que aí se fazem presentes, através dos diferenciais de capacidade que cada um tem 
de afetar as ações de outro, produzindo certos efeitos. São modos de relação marcados pelo poder que dão forma à produção de saber e à produção dos sujeitos que transitam no ambiente universitário.

No entanto, a presença e ação do poder não se circunscrevem ao funcionamento das instituições como a universidade. A própria universidade é produzida pelas relações de poder e saber que circulam em todo tecido social.

\section{Poder e saber: conduzir condutas, conduzir balões}

Para Nietzsche (1998 apud VEIGA-NETO, 2016), onde há vida, há vontade de poder, referindose ao que Foucault, posteriormente, estudou de maneira detalhada, ao tratar o poder como força coextensiva a todo corpo social, da qual ninguém está imune. De acordo com as ideias de Michel Foucault (1993; 1999; 2006), o poder está em toda a parte: na sociedade, nas relações e nos pequenos enfrentamentos, sendo responsável pelo movimento de produção de verdade e de subjetividade, através dos mecanismos diversos que engendra. Ele se produz e se capilariza nas relações de produção, de ensino, de sexualidade, de família etc., dando uma configuração determinada ao modo como essas relações acontecem e são entendidas.

O poder não é uma coisa, uma instituição ou uma estrutura, nem emana de uma fonte central, como o Estado; refere-se mais a "um lugar estratégico, onde se encontram todas as relações de força poder/saber" (FOUCAULT, 2006, p.231). Ainda que ele possa ser induzido pelo aparelho do Estado, sendo fundamental para seu funcionamento, não se reduz a ele, tendo múltiplas origens. O poder funciona em rede, passando pelos indivíduos, que o transmitem, exercendo-o e sendo alvo dele, bem como ponto de resistência a esse poder, na mesma rede em que ele se desenrola (VEIGA-NETO, 2016).

O poder pressupõe relações de poder e isso implica dizer que não há uma dominação unilateral, pois, o ele nasce de "uma pluralidade de relações que se enxertam uma na outra" (FOUCAULT, 2006, p. 276), sinalizando a resistência, a luta entre o poder e o poder, e não sobre o poder e o não- poder.

O poder só se exerce sobre sujeitos "livres", enquanto "livres"- entendendo-se por isso sujeitos individuais ou coletivos que têm diante de si um campo de possibilidade onde diversas condutas, diversas reações e diversos modos de comportamento podem acontecer. Não há relação de poder onde as determinações estão saturadas [...], mas apenas quando ele pode se deslocar e, no limite, escapar. Não há, portanto, um confronto entre poder e liberdade, numa relação de exclusão (onde o poder se exerce a liberdade desaparece) (FOUCAULT, 1995, p. 244).

Poder e resistência mantêm uma espécie de relação agonística, na qual um não anula o outro, mas se afirmam num jogo de incitação mútua: a liberdade é condição de existência do poder; sem ela, não há relação de poder, mas sim uma situação de coerção pura e dominação. Ao mesmo tempo, essa liberdade é forjada na relação com o poder, pois este a modula, quando dispõe um certo campo de possibilidades de 
ação. Por isso, as relações de poder tendem a ser sutis: não de dominação brutal, mas de enfrentamentos de forças, podendo ser reversíveis. Há espaço para a liberdade, e, com isso, mudanças nas formas de incidência do poder e nas formas de resistência a ele (FOUCAULT, 1995).

Essa sutileza e invisibilidade nos mecanismos de ação do poder retrata, segundo Deleuze (1992), uma transição de um modelo de sociedade disciplinar, por volta do século XX, para um modelo de sociedade de controle, na qual o poder passa a estar cada vez menos associado a mecanismos externos, e adquire uma conotação mais imaterial, através dos modos de subjetivação característicos da ascensão e domínio capitalista. Assim, ele, que já se distribui por toda parte, de forma capilar e molecular, numa microfísica do poder, torna-se ainda mais insidioso nos corpos e nas condutas, por já não se associar estritamente aos espaços disciplinares. Agora, incide "a céu aberto", tendendo a ser indissociável dos próprios corpos e condutas, de acordo com as características do contexto político, econômico e social.

A incidência do poder tende a deslizar sutilmente, modulando aquilo que somos, pois ele não reprime. Há no poder uma positividade: ele oferece possibilidades, ideias, valores, condutas, produzindo com isso modos de ser. É justamente por isso que ele é aceito e naturalizado, desde a instância de governo dos outros até o governo de si mesmo. Se ele só fosse repressivo, trazendo só proibições para a vida, tornarse-ia excessivamente evidente e facilmente repelido. Mas, não: sua apresentação é atrativa e enreda com muita facilidade; ele manda fazer coisas, ele dispõe possibilidades, conduzindo as condutas ao estabelecer um campo de ações possíveis. Com isso, o poder não proíbe, mas elege algumas possibilidades em detrimento de outras, que não são vistas, e, caso sejam, não têm validade ou valor de verdade (FOUCAULT, 1993).

A vontade de poder se produz "no jogo das práticas concretas que, diante do diferencial em que as situações concretas se estabelecem, buscam satisfazer interesses e acabam por conferir legitimidade" (VEIGA-NETO, 2016, p.123), como podemos perceber na "legitimidade" adquirida nos modos de funcionamento universitário expostos pelos balões. No entanto, o exercício de poder não se faz diretamente sobre os sujeitos, mas sobre suas ações:

Ele é um conjunto de ações sobre ações possíveis; ele opera sobre o campo de possibilidade onde se inscreve o comportamento dos sujeitos ativos; ele incita, induz, desvia, facilita ou torna mais difícil, amplia ou limita, torna mais ou menos provável; no limite, ele coage ou impede absolutamente, mas é sempre uma maneira de agir sobre um ou vários sujeitos ativos, e o quanto eles agem ou são suscetíveis de agir. Uma ação sobre ações (FOUCAULT, 1995, p. 243).

Vejamos que não se trata de algo distante ou externo, nem da ordem do consenso ou do consentimento. $\mathrm{O}$ exercício de poder se dá nas relações que atravessam todo tecido social, produzindo 
modos de ver e de fazer coisas, de se relacionar consigo e com outro, a partir do qual se produzem estatutos de verdade, com base nos quais as pessoas e situações são analisadas e categorizadas.

No que toca a história dos balões, ao pensar sobre o papel do professor, não parece que estamos falando de um carrasco, pelo menos, não de um carrasco clássico, que tortura meticulosamente seus condenados, tal como Foucault (1999) nos fala do poder soberano, centralizado no rei, tendo caráter eminentemente repressor. Na história dos balões, falamos de um mestre que é "respeitado" pelo silêncio que seus títulos impõem, pelo modo como esses títulos e suas experiências são exaltados, pelos lugares de destaque ocupados, pelo extenso currículo de infindáveis publicações e "gloriosos" feitos. Também não parece que estamos falando dos alunos como indefesas vítimas, sujeitas a uma tortura alucinante, ainda que as posições de poder de alunos e mestres sejam diferenciadas. Estou falando de pessoas que também podem aceitar as regras do jogo, de forma deliberada ou não, pelos resultados almejados em tal jogo; ou mesmo pela crença de que aquela é a melhor forma de se fazer o que "deve" ser feito - fazer a disciplina acontecer em determinados moldes.

Com isso, falamos, sobretudo, de relações naturalizadas, para as quais a instituição não só dá suporte, como as produz, por vezes, de forma sutil, por se diluírem ou se justificarem nas práticas e discursos de ensinar e aprender, pelos quais a instituição funciona e para os quais ela funciona. E, nesse sentido, os balões cheios e vazios, assim como aqueles que lhes dão direção, e a configuração de relações estabelecidas parecem nos falar de certos modos de ser que vão se construindo por tais relações, para, assim, nelas estar.

Nesse processo, o poder mantém uma relação indissociável com o saber. Para que o poder se afirme e que as possibilidades que ele oferece sejam vistas como válidas, é necessário um campo de saber que lhe dê sustentação, que justifique que as coisas sejam pensadas e vividas de um determinado modo, fazendo com que elas sejam vistas como necessárias e aceitas. Da mesma forma, para a construção e afirmação de um saber, é necessária uma certa configuração de poder, para que um saber específico emerja dentre outros possíveis: "Os saberes se engendram e se organizam para atender a uma vontade de poder" (VEIGA-NETO, 2016, p. 115).

Nessa perspectiva, o saber não é visto como uma faculdade humana, mas como um acontecimento articulado ao poder, que tem uma construção histórica, aparecendo a partir de determinadas configurações, formas, funções e valor. O tratamento dado por Foucault ao saber não se localiza nas concepções da epistemologia tradicional, na qual o conhecimento é visto como algo a priori da experiência, e que ultrapassa seus limites. Sua perspectiva se localiza numa espécie de epistemologia social, que rejeita a unidade do conhecimento e que entende que a origem dos saberes e seus arranjos não são naturais, mas remetem a uma perspectiva social e relacional. É esse caráter relacional, social, subjetivo que tende a ser 


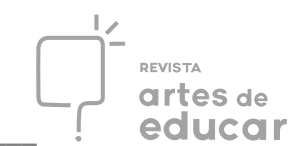

desconsiderado, e até negado, na maior parte dos espaços de produção de saber, mas que diz respeito direta ou indiretamente ao modo como o poder ali se faz presente e circula (VEIGA-NETO, 2016).

Cabe enfatizar que, mesmo indissociáveis, poder e saber têm naturezas diferentes: enquanto o saber se constitui por formas relativamente rígidas, por enunciados e visibilidades, que constituem estratos, o poder é constituído por relações de forças móveis, que afetam e são afetadas. Daí, ele não ser algo concreto, nem localizável; ele circula pelas relações, atravessando as formas de saber, de forma capilar por todos os âmbitos da vida.

O poder se dá numa relação flutuante, isso é, não se ancora numa instituição, não se apoia em nada fora de si mesmo, a não ser no próprio diagrama estabelecido pela relação diferencial de forças; por isso, o poder é fugaz, evanescente, singular e pontual. O saber, bem ao contrário, se sustenta nas matérias/conteúdos e em elementos formais que lhes são exteriores: luz e linguagem, olhar e fala. É bem por isso que o saber é apreensível, ensinável, domesticável, volumoso. E poder e saber se entrecruzam no sujeito, seu produto concreto, e não num universo abstrato (VEIGA-NETO, 2016, p. 128).

Os saberes são espécies de estratos, que se constituem a partir daquilo que é possível ver e dizer num determinado momento histórico. Ou seja, não vemos ou falamos das coisas das mesmas formas desde sempre, nem fazemos isso de maneira aleatória. Em cada formação histórica, há "regimes de luminosidade", que produzem o "visível”, e formas de enunciados para o que se faz “dizível”. O saber, então, é um agenciamento de visibilidades e enunciados, que têm certas formas, que se relacionam, mas que não se confundem e não dependem diretamente uma da outra: o que vemos não cabe no que dizemos, e o que dizemos não cabe no que vemos (LEVY, 2003).

Então, o complexo saber-poder une os diagramas de força do poder com os arquivos do dizível e do visível do saber. Quando o poder faz ver e falar, há a passagem do plano virtual, do devir e das matérias não formadas, para o plano atual, o das formas, e, assim, o complexo saber-poder vai se atualizando de diferentes modos a cada formação histórica (idem).

Essa indissociabilidade do poder e do saber, que atravessa as relações de todo tecido social pode ser visualizada de maneira mais clara nos processos pedagógicos, como os que estão imbrincados na história dos balões cheios e vazios.

[...]o processo pedagógico corporifica relações de poder entre professores e aprendizes (definidos, seja de forma estreita, para se referir aos atores na educação institucionalizada, seja de forma ampla, para se referir a outras relações pedagógicas, tais como se dão entre pais e filhos, escritores e leitores e assim por diante) com respeito a questões de saber: qual saber é válido, qual saber é produzido, o saber de quem. A pedagogia se baseia em técnicas particulares de governo, cujo desenvolvimento pode ser traçado 
historicamente/arqueologicamente, e produz e reproduz, em diferentes momentos, regras e práticas particulares" (GORE, 2011, p. 13-14).

E isso remete à metodologia aplicada aos balões da narrativa, metodologia que não é só do professor, mas que parece dar concretude às engrenagens institucionais, nas quais tanto ele quanto os alunos e a SAES estão inseridos e se produzindo. Talvez, essa seja uma excelente metodologia mesmo; talvez, ela já tenha produzido excelentes resultados; não é a qualidade da metodologia que está em questão. O que se coloca em relevo é o estatuto que ela adquire e o fato de pouquíssimas pessoas, nessa situação, conseguirem se fazer caber no molde da dita metodologia; é o fato de ela permanecer "naturalizadamente" imutável ao longo dos períodos letivos, das turmas e dos anos, como máquina de reprovação e fracasso educacional. A metodologia se encontra justificada por saberes e poderes, que lhe dão esse lugar, que tenta lhe manter imune a mudanças e questionamentos.

\section{Produção de balões: o gás do assujeitamento}

A história dos balões cheios e vazios vai mostrando, pela queixa de sintomatização diante do baixo desempenho, das reprovações sucessivas e do esvaziamento das experiências na universidade, modos pelos quais podemos transitar por esses terrenos produzidos nas relações de saber e poder, que são engendradas na dinâmica universitária. Ao entrarmos na universidade, a universidade também vai “entrando" na gente, como parte do processo que costumamos chamar de adaptação. Adaptar-se parece ser assimilar determinados modos de habitar, transitar e se relacionar com as pessoas e as coisas que nela acontecem, chegando-se num ponto em que tudo tende a parecer muito natural. É o processo de nos tornarmos "sujeitos da educação"iv , sujeitos “educados" pelas relações de poder-saber.

Para Foucault (1995), a questão do poder sempre esteve relacionada ao modo como nós produzimos e somos produzidos enquanto sujeitos.

Esta forma de poder aplica-se à vida cotidiana imediata que categoriza o indivíduo, marca-o com sua própria individualidade, liga-o à sua própria identidade, impõelhe uma lei de verdade, que devemos reconhecer e que os outros têm que reconhecer nele. É uma forma de poder que faz dos indivíduos sujeitos. Há dois significados para a palavra sujeito: sujeito a alguém pelo controle e dependência, e preso à sua própria identidade por uma consciência e autoconhecimento. Ambos sugerem uma forma de poder que subjuga e torna sujeito a (FOUCAULT, 1995, p. 235).

Não somos simplesmente seres humanos; somos seres humanos tornados sujeitos; sujeitos a uma lógica, sujeitos a um determinado modo de entendimento e funcionamento, o que não quer dizer que esse seja um processo estritamente coercitivo, pois vamos internalizando tais sujeições como coisas naturais. As pessoas são objetivadas de determinadas formas e parâmetros, dentro de determinadas racionalidades 
políticas e de saber, que visam transformá-las em sujeitos, em determinados tipos de sujeito, de acordo com o que é demandado em cada momento histórico e em cada situação específica. Na história dos balões cheios e vazios, há uma demanda colocada de "necessidade" de adaptação a metodologias de ensino e de pesquisa, que produzem "impasses" nos balões que se põem a esvaziar, porque, ao mesmo tempo em que discordam da metodologia, querem se fazer caber nelas; esvaziam quando constatam que não estão conseguindo.

Tornar-se sujeito, estar sujeito a uma lógica e a um modo de funcionamento determinado não é da ordem da coerção. Trata-se de uma sujeição voluntária, parafraseando La Boétie, quando abordado por Clastres (2004) ao falar da "servidão voluntária", esse ato de nos submetermos voluntariamente a um poder, pois "a atividade própria do sujeito torna-se parte interessada do processo pelo qual ele é posto como sujeito" (KARSENTI, 2013, p. 6). É o que Bruno Karsenti (2013) chama de assujeitamento, referindo-se a complexos processos, pelos quais nos submetemos ao poder, sem que isso signifique uma violência ou pura coerção, pois se faz como um processo de subjetivação, um certo modo pelo qual construímos uma relação conosco e com o mundo. Essa modalidade de sujeição não implica num apagamento do sujeito, da sua ação, nem lhe priva da liberdade; o poder se exerce justamente produzindo as condições para que o sujeito seja, faça, aja, entenda, pense, sinta, viva, etc. (KARSENTI, 2013).

Diante disso, vemos que a história dos balões cheio e vazios fala de assujeitamento, pois nos modos de habitar a universidade, há uma ambiguidade fundamental: é um lugar em que somos impelidos a estar, por toda uma expectativa pessoal e social, e submetidos quando nele estamos, mas, principalmente, o lugar em que nos sujeitamos a estar. Dizer que há uma relação de submissão em relação ao funcionamento universitário é entender que os mecanismos de poder nos pegam pelos pés nesse contexto, nos impelem a fazer coisas, amarram-nos em certos sentidos. E dizer que nos sujeitamos a isso é também saber que vamos com nossos próprios pés para esses lugares, porque neles desejamos estar.

É a produção do próprio sujeito o que está em jogo nessa forma de sujeição ao poder. E quando falamos em produção é para ressaltar o caráter positivo do poder, que ele faz coisas, que ele nos dispõe as possibilidades de fazer coisas, subjugando-nos através disso, sem que achemos que o estamos sendo. Um paradoxo; ou nem tanto. Talvez, sejam nossos modos dicotômicos de ver as coisas que levem a chamar de paradoxo a presença simultânea, numa mesma configuração, de interdição e "liberdade". Por isso que o poder em si não existe; não existe numa concepção puramente jurídica, carregada pela restrição, uniformidade, impositividade, que proíbe, que diz “não". O poder diz “sim”, muitos “sins”. Ele é móvel e inventivo, atualizando-se de formas diferentes de acordo com as particularidades do plano em que ele intervém. E, com isso, produz um efeito de regulação em toda parte, em todos os âmbitos da vida (KARSENTI, 2013). 
Poder plenamente positivo que, no próprio processo de sua lógica interna, vai necessariamente, até afirmar seu "outro", não simplesmente para lhe dar permissãoo que introduziria apenas uma exceção no regime da interdição- mas, ao contrário, para se servir disso no âmbito de uma estratégia determinada e para constituí-lo como ponto de apoio na sua efetuação (KARSENTI, 2013, p. 4).

É na ordem das ações, de ordenamento das condutas que ele atua; faz-se uma espécie de governo das condutas. Esse é o jogo pelo qual o poder se efetiva; é o jogo do assujeitamento, que requer sujeitos livres, que dispõe de possibilidades, as quais aparecem de forma contemporânea à produção das subjetividades; nem a priori, nem a posteriori: no mesmo momento. Assim:

[...] a conduta dos sujeitos, a maneira de se conduzir, as formas por meio das quais o sujeito problematiza-se e concebe sua ação, são efeitos, apenas na medida em que são também causas eficientes do assujeitamento- este último devendo ser entendido não no sentido negativo de obediência a uma norma, mas naquele positivo, de um certo posicionamento dos indivíduos pelo qual eles próprios se constituem como sujeitos. [...] $\mathrm{O}$ assujeitamento é, nele mesmo, um processo afirmativo de subjetivação, e deve, por esta razão, ser considerado a partir das práticas subjetivas que ele põe em jogo (KARSENTI, 2013, p. 7).

Se o poder é entendido como positivo e o assujeitamento como um processo afirmativo de subjetivação, então, não podemos considerar que há uma total submissão ou alienação dos sujeitos. Nesse jogo, submissão e insubmissão coexistem e se sustentam. E não é por incapacidade do poder que isso acontece; é por sua própria forma de funcionamento, que requer sujeitos livres, que fazem das resistências partes constituintes do jogo, como se fosse uma tensão permanente entre poder e resistência. Há uma relação agonística, de confronto entre eles, sem que se excluam; constituem-se mutuamente: poder requer resistência e resistência requer poder, como se um fosse o limite, ainda que instável, do outro. E como afirma Karsenti (2013), essa relação não constitui um sistema fechado em que as resistências, inevitavelmente são tragadas pelo poder, em que as lutas que se propõem resistência e contestação acabam jogando contra si mesmas.

\section{Um pouso e algumas considerações}

A história do balão se esvaziando mostra que, mesmo quando há a identificação de um funcionamento de curso ou de metodologias desfavoráveis ou incompatíveis com as turmas, o que se busca é o tratamento do sintoma individual para conseguir desempenho exitoso, para conseguir se encaixar no que está sendo impositivamente solicitado em termos de atividades e desempenho, ainda que isso muito incomode. Sim, parece "solicitação imposta": solicitação porque, em tese, ninguém é obrigado a fazer as coisas de tais formas, submetendo-se e se fazendo caber nos moldes dados; imposta porque, do modo como 
são colocadas, é como se não houvesse nada "melhor", além do oferecido. E nisso, vemos como esse processo de assujeitamento vai dando direções ao voo, conduzindo condutas e produzindo certos modos de ser, de nos relacionarmos conosco, com o outro e com o que fazemos. E por esse processo que vamos nos produzindo como sujeitos, com uma determinada experiência de si.

Dessa forma, nesses trechos de UFS, nos quais habitam os balões se esvaziando, se for para nele estar, que seja com os pés no chão, ignorando as pedras no meio do caminho e os tropeços nelas, parafraseando Carlos Drummond de Andrade (1967). Que o corpo se mantenha em silêncio! Quando ele fala, costuma "atrapalhar" o encaminhamento das coisas. E se for para tirar os pés do chão, que o voo se faça na direção e velocidade apontadas pelo mestre-condutor, enquanto ponto de transmissão da rede de relações institucionais; é ele quem sabe das coisas; ou a ele é dado o poder de saber das coisas. Talvez, o esperado é que a SAES possa "ajudar" nessa tarefa no silenciamento do corpo e na velocidade da caminhada e do voo! Muitas vezes, é essa a expectativa embutida na demanda de tratamento do sintoma, como se ele estivesse dissociado da dinâmica institucional e de suas relações. São os tombos na caminhada que abrem a possibilidade de questionar e recusar esse tipo de função

Diante disso, será que dá para encher o balão na universidade? De que tipo de gás vamos dispondo para tal?

Pelos processos de subjetivação que o contexto universitário aqui engendra, entrar e permanecer nele sugere uma certa adaptação, um modo de ser "coerente" com o que nele é esperado do sujeito. Adaptarse parece ser o momento em que vamos enchendo os balões com o gás disposto, imposto ou exigido, para nos tornarmos sujeitos da educação; é o momento em que tendemos a nos assujeitar às conduções do voo, ou também produzir estranhamentos, como sugerem os "balões que secam".

O que isso nos diz é que os movimentos, histórias de vida e singularidades que entram, habitam e transitam no "mundo-universidade" parecem muito com o movimento do balão cheio de gás que consegue flutuar, o que, muitas vezes, mostra-se em descompasso com modos esperados de estar na universidade. Talvez, esses modos nem sempre "sequem" nossos balões; muitas vezes, até nos sejam oferecidos outros tipos de "gases", mas tipos que parecem não fazer o balão flutuar; ou ainda, tipos que façam com que ele flutue e flutue muito, mas flutue segurado por cordão. Se pelas definições de Foucault (1995), o poder conduz condutas, produzir balões é, sobretudo, conduzir a direção do voo para o modo "sujeito da educação", sujeito a outrem, sujeito ao que impõe a si mesmo, ponto no qual parecem se confundir o que busca e o que lhe é imposto.

Nas tentativas de voo do balão murcho, chamam a atenção os "acordos" tácitos que alimentam essa dinâmica. É o jogo em que temor e estratégia convivem num mesmo território; jogo esse que se dá com muitos, mas do qual se fala pelo lugar individual, principalmente, quando é exposta a dificuldade de seguir as direções de voo apontadas. É esse balão que anuncia que há balões se esvaziando, muitos balões 
além dele, que se incomoda por não se sentir favorecido pelo jogo, pois gostaria de se dar bem nele, porque pretende enveredar por estes caminhos da vida acadêmica. Quem se vê favorecido pelo jogo, aparentemente, não se queixa dele. Ainda assim, é esse mesmo balão que quer sobreviver, reinventar-se e descobrir de que outras formas é possível flutuar na universidade.

Diante disso, entendemos que pensar a produção de subjetividade, seguindo as pistas da experiência de si, pelas relações de poder-saber na vida universitária, no recorte da assistência estudantil, é sermos tombados pelo assombro diante daquilo que se mostra naturalizado. É esse "tombo" que pede o "não" ao que é intolerável e insinua a "pergunta" que questiona de que outras formas é possível habitar este terreno, sem nos deixar tragar pelas armadilhas que ele dispõe, como coloca Larrosa (2014).

Pensando com Blanchot (2010), a fuga dessas armadilhas parece se fazer na impossibilidade de fugir, de buscar esconderijo: estamos na vida universitária, é dela que dispomos, é nela que nos expomos, é nela que nos produzimos. A fuga é a própria exposição, o pensar possibilidades do que fazer quando esse "constrangimento" dos balões que secam é exposto, expondo consigo a engrenagem universitária, e trazendo nisso muitas ambiguidades, que as saídas dicotômicas e prescritivas parecem não dar conta. E, nessa fuga, parece estar aquilo que Foucault (1995) chama de recusa:

Talvez, o objetivo hoje em dia não seja descobrir o que somos, mas recusar o que somos. Temos que imaginar e construir o que poderíamos ser para nos livrarmos deste "duplo constrangimento" político, que é a simultânea individualização e totalização própria às estruturas de poder moderno. A conclusão seria que o problema político, ético, social e filosófico de nossos dias não consiste em liberar o indivíduo do Estado nem das instituições do Estado, porém nos liberarmos tanto do Estado quanto do tipo de individualização que a ele se liga. Temos que promover novas formas de subjetividade através da recusa desse tipo de individualidade que nos foi imposto há vários séculos. (FOUCAULT, 1995, p. 239).

E assim, vemos que os balões que chegam à SAES podem não dar fórmulas para flutuar neste terreno universidade. Mas, certamente, eles conseguem expor modos como operam as relações de saberpoder que na universidade circulam, produzindo aquilo que vamos nos tornando, ao mesmo tempo em que sinalizam o que faz tombar o voo e o que pode ser recusado. É repetitivo dizer que não há fórmulas para essa recusa; se houvesse, já não seria recusa, só reprodução. Recusa é fuga, é invenção onde estamos, pelo que dispomos nesses encontros, nesta realidade universitária de todos os dias.

\section{Referências}

ANDRADE, Carlos Drummond. Uma pedra no meio do caminho. In: . Biografia de um poema. Rio de Janeiro: Editora do Autor, 1967. 
BLANCHOT, MAURICE. A questão mais profunda. Tradução de Aurélio Guerra Neto. In: . A conversa infinita. São Paulo: Escuta, 2010. p. 41- 61.

BRASIL. Decreto n 7.234 , de 19 de julho de 2010. Dispõe sobre o Programa Nacional de Assistência Estudantil - PNAES. Disponível em:< http://www.planalto.gov.br/ccivil_03/_ato20072010/2010/decreto/d7234.htm>. Acesso em 22 abr. 2020.

CLASTRES, Pierre. Liberdade, Mau encontro, inominável. In: Arqueologia da violência: pesquisas de antropologia política. São Paulo: Cosac \& Naify, 2004. p. 107- 119.

DELEUZE, Gilles. Pós-scriptum sobre as sociedades de controle. In: DELEUZE, Gilles. Conversações. São Paulo: Ed 34, 1992. p. 219-226.

FERREIRINHA, Isabela Maria Nunes; RAITZ, Tânia Regina. As relações de poder em Michel Foucault: reflexões teóricas. Revista de Administração Pública, Rio de Janeiro, v. 44, n. 2, p. 367-383, abr. 2010. Disponível em:< http://www.scielo.br/scielo.php?script=sci_arttext\&pid=S0034$76122010000200008 \& \operatorname{lng}=e n \& n r m=i s o>$. Acesso em: 20 jun. 2019.

FONAPRACE, Fórum Nacional de Pró-reitores de Assuntos Comunitários e Estudantis. Revista Comemorativa 25 Anos: histórias, memórias e múltiplos olhares. Organizado pelo Fórum Nacional de Próreitores de Assuntos Comunitários e Estudantis, coordenação, ANDIFES. - UFU, PROEX : 2012. Disponível em: http://www.proae.ufu.br/central-de-conteudos/documentos/2012/10/revistacomemorativa-25-anos-de-fonaprace>. Acesso em: 19 jun. 2019.

FOUCAULT, Michel. Microfísica do poder. Organização e tradução de Roberto Machado. Rio de Janeiro: Edições Graal, 1993.

FOUCAULT, Michel. Vigiar e Punir: nascimento da prisão. Tradução de Raquel Ramalhete. 20 ed. Petrópolis: Vozes, 1999.

FOUCAULT, Michel. O sujeito e o poder. In: RABINOW, P.; DREYFUS, H. Michel Foucault: uma trajetória filosófica (para além do estruturalismo e da hermenêutica). Rio de Janeiro: Forense Universitária, 1995. p. 231-249.

FOUCAULT, Michel. Estratégia, poder-saber. Organização e seleção de textos: Manoel Barros da Motta. Tradução Vera Lúcia Avelar Ribeiro. $2^{a}$ ed. Rio de Janeiro: Forense Universitária, 2006. p. 221-305. Coleção: Ditos \& Escritos IV.

GORE, Jennifer M. Foucault e a educação: fascinantes desafios. In: SILVA, Tomaz Tadeu (org). O sujeito da educação: estudos foucaultianos. 8 ed. Petrópolis, RJ: Vozes, 2011. p. 09- 20.

HASKINS, Charles Homer. A Ascensão das Universidades. Balneário Camboriú: Livraria Danúbio Editora, 2015.

KARSENTI, Bruno. Poder, assujeitamento, subjetivação (tradução não publicada). Texto originalmente publicado na revista Antérieur, n. 10, 1992, republicado na Entre-là em 14 de março de 2013. Disponível $\mathrm{em}:<\mathrm{http}: / / \mathrm{xn}$--entre-l-fwa.net/pouvoir-assujettissement-subjectivation-par-bruno-karsenti/>. Acesso 10 out. 2019.

LARROSA, Jorge. Notas sobre a experiência e o saber de experiência. Rev. Bras. Educ., Rio de Janeiro, n. 19, p. 20-28, abr. 2002. Disponível em: <http://www.scielo.br/scielo.php?script=sci_arttext\&pid=S1413$24782002000100003 \& \operatorname{lng}=\mathrm{en} \& n r m=$ iso $>$. Acesso em $15 \mathrm{dez} 2019$.

LARROSA, Jorge. O ensaio e a escrita acadêmica. Educação e realidade, n. 28, v. 2. 2003. p 101-115. Disponível em: https://seer.ufrgs.br/educacaoerealidade/article/view/25643>. Acesso em 15 nov. 2019.

LARROSA, Jorge. Tecnologias do eu e educação. In: SILVA, T. T (org). O sujeito da educação: estudos foucaultianos. Petrópolis: Vozes, 2011. p. 35-86. 
LARROSA, Jorge. Ferido de realidade e em busca de realidade: Notas sobre as linguagens da experiência.

In: Tremores: escritos sobre a experiência. Belo Horizonte: Autêntica, 2014. Coleção: Experiência e Sentido. p. 73-122.

LEVY. Tatiana Salem. A experiência do Fora: Blanchot, Foucault e Deleuze. Rio de Janeiro: Relume Dumará, 2003.

SILVA, Rosane Neves. A invenção da Psicologia Social. Petrópolis: Vozes, 2005.

SILVA, Franklin Leopoldo. Universidade: a ideia e a história. Estudos Avançados, n. 20, v. 56, 2006. Disponível em:< http://www.revistas.usp.br/eav/article/view/10129>. Acesso em: 21 jun. 2019.

TRINDADE, Hélgio. Saber e poder: os dilemas da universidade brasileira. Estudos avançados, São Paulo, v.14, n. $40, \quad$ p. 122-133, 2000. Disponível $\quad$ em:< http://www.scielo.br/scielo.php?script=sci_arttext\&pid=S0103-40142000000300013 >. Acesso em: 20 jun. 2019.

UNIVERSIDADE FEDERAL DE SERGIPE. Resolução nº 08/2016/CONSU. Altera Normas que tratam de Auxílio à Assistência Estudantil da Universidade Federal de Sergipe. Disponível em: $<$ http://proest.ufs.br/uploads/page_attach/path/867/082016___acoes_assistencia_estudantil.pdf.>. Acesso em: 30 mai. 2019.

VEIGA-NETO, ALFREDO. Foucault \& a Educação. 3. Ed. Belo Horizonte: Autêntica Editora, 2016.

Recebido em: 29/04/2020.

Aceito em: 17/06/2020.

\title{
Notas
}

\begin{abstract}
i Possui graduação em Psicologia (2013) pela Universidade Federal de Sergipe, pós-graduação em Psicopedagogia pela Universidade Católica Dom Bosco (2016), e mestrado em Psicologia (2020) pelo Programa de Pós-Graduação em Psicologia da Universidade Federal de Sergipe, na linha Processos de Subjetivação e Política. Desde 2014, é psicóloga da Universidade Federal de Sergipe, desenvolvendo atividades no campo da assistência estudantil. E-mail: edileuzasnc@bol.com.br Sergipe. ORCID: http://orcid.org/0000-0002-9064-2220

ii Possui graduação em Psicologia pela Universidade Santa Úrsula (1992), mestrado em Psicossociologia de Comunidade e Ecologia Social pela Universidade Federal do Rio de Janeiro (1998) e doutorado em Psicologia Social pela Universidade do Estado do Rio de Janeiro (2007). Atualmente é professor associado do Departamento de Psicologia e professor permanente do Núcleo de Pós-graduação em Psicologia Social da Universidade Federal de Sergipe. Tem experiência atuando principalmente nos seguintes temas: história da psicologia, práticas psicológicas, assistência infanto-juvenil, direitos da infância e juventude. Email: marceloferreri@uol.com.br Sergipe. ORCID: http://orcid.org/0000-0001-7562-8124

iii Este artigo é um recorte da dissertação de mestrado "Caminhando por histórias da UFS: a produção da experiência de si pelas relações de poder-saber que se cruzam na SAES”, apresentada ao Programa de Pós-graduação em Psicologia da Universidade Federal de Sergipe, em março de 2020. Nela, abordamos os processos de subjetivação pelas relações de poder-saber, que se cruzam na assistência estudantil de um campus de uma universidade pública federal, no interior do estado de Sergipe. Pela ocupação do lugar e pelo estranhamento do olhar da Psicologia na Secretaria de Assistência Estudantil (SAES) do Campus Professor Alberto Carvalho da Universidade Federal de Sergipe, procuramos identificar modos como o funcionamento disparado por tais relações vão modulando a experiência de si naqueles que compõem tal contexto. Isso se fez através de situações tecidas e historiadas, principalmente, no contato com o discente, público alvo da assistência estudantil, ainda que se entenda que as
\end{abstract}


relações de poder-saber, de algum modo, atravessem todos aqueles que habitam o terreno universidade, assim como todo tecido social.

iv Em referência ao título do livro "O sujeito da educação: estudos foucaultianos”, organizado por Tomás Tadeu da Silva, publicado pela editora Vozes, em 2011. 